\title{
Thermal desorption spectroscopy studies of hydrogen desorption from rare earth metal trihydrides $\mathrm{REH}_{3}(\mathrm{RE}=\mathrm{Dy}, \mathrm{Ho}, \mathrm{Er})$
}

\author{
S. Suwarno ${ }^{\text {a, }}$, M.V. Lototskyy ${ }^{\text {b }}$, V.A. Yartys ${ }^{\text {c, }}{ }^{* *}$ \\ a Department of Mechanical Engineering, Institut Teknologi Sepuluh Nopember, Surabaya, 60111, Indonesia \\ ${ }^{\mathrm{b}}$ HySA Systems Centre of Competence, South African Institute for Advanced Materials Chemistry, University of the Western Cape, P. Bag X17, Bellville, 7535, \\ South Africa \\ ${ }^{\mathrm{c}}$ Institute for Energy Technology, P.O. Box 40, NO-2027, Kjeller, Norway
}

\section{A R T I C L E I N F O}

\section{Article history:}

Received 25 November 2019

Received in revised form 2 May 2020

Accepted 5 May 2020

Available online 15 May 2020

\section{Keywords:}

Rare earth hydride

Thermal desorption spectroscopy

Hydrogen desorption

Kinetics

\begin{abstract}
A B S T R A C T
Rare earth (RE) metals form two stoichiometric hydrides, $\mathrm{REH}_{2}$ and $\mathrm{REH}_{3}$, and for the yttrium group of RE transformation of a FCC $\left(\mathrm{REH}_{2}\right)$ into an $\mathrm{HCP}\left(\mathrm{REH}_{3}\right)$ lattice takes place during the second step of hydrogenation $\mathrm{REH}_{2}+1 / 2 \mathrm{H}_{2} \rightarrow \mathrm{REH}_{3}$. Earlier studies of the hydrogen desorption properties of the rare earth hydrides were limited to $\mathrm{Y}$ and $\mathrm{RE}=\mathrm{La}, \mathrm{Ce}, \mathrm{Pr}, \mathrm{Nd}, \mathrm{Sm}, \mathrm{Gd}$, Tb and Er. The present work is focused on the studies of the kinetics and mechanism of hydrogen desorption from trihydrides of heavy rare earths, $\mathrm{DyH}_{3}, \mathrm{HoH}_{3}$, and $\mathrm{ErH}_{3}$. The Thermal Desorption Spectroscopy (TDS) studies were performed at pressures below $1 \times 10^{-5}$ mbar during linear heating from room temperature to $1173 \mathrm{~K}$ at different heating rates ranging from 1 to $5.5 \mathrm{~K} / \mathrm{min}$. Hydrogen desorption traces show the presence of two main events with the low-temperature peak appearing below $573 \mathrm{~K}$, while the second peak is positioned at $1083-1159 \mathrm{~K}$, with the peak temperatures gradually increasing following the rise of the heating rate. Fitting of the peak temperatures in the TDS spectra using the Kissinger method yielded activation energies of hydrogen desorption for both hydrogen desorption events. For $\mathrm{DyH}_{3}$ and $\mathrm{ErH}_{3}$, the shapes of the TDS spectra appear to be well described by a phase-stuctural transformation following a model of nucleation and growth, while for $\mathrm{HoH}_{3}$ the dehydrogenation mechanism includes a phase boundary reaction. This applied model of phase-structural transformations shows differences in dimensionality and rate-limiting steps as related to the studied compound and the desorption events, $\mathrm{REH}_{3} \rightarrow \mathrm{REH}_{2}$ or $\mathrm{REH}_{2} \rightarrow \mathrm{RE}$.
\end{abstract}

(c) 2020 Elsevier B.V. All rights reserved.

\section{Introduction}

Rare earth (RE) metals react with hydrogen consequitively forming di- and trihydrides, while the hydrogenation affects magnetic and electronic properties as related to the hydrogen content in the hydride phase. Studies on individual RE metals and their alloys have attracted many investigators and were focused on the development of their applications as the components of the hydrogen storage materials [1], metal hydride battery anodes [2,3], and gas sensors [4]. Practical importance of the RE hydrides is also related to the Hydrogenation-Disproportionation-DesorptionRecombination (HDDR) process in RE-containing Me-H systems allowing manufacturing of RE-Fe-B permanent magnets with high

\footnotetext{
* Corresponding author.

** Corresponding author.

E-mail addresses: warno@me.its.ac.id (S. Suwarno), volodymyr.yartys@ife.no (V.A. Yartys).
}

energy product [5].

Both hydrides of rare earth metals are formed as stoichiometric compounds, $\mathrm{REH}_{2}$ and $\mathrm{REH}_{3}$, and for the yttrium group of RE metals, a transformation of the FCC $\left(\mathrm{REH}_{2}\right)$ into the HCP $\left(\mathrm{REH}_{3}\right)$ hydrides takes place during the second step of hydrogenation. The formation of super stoichiometric dihydrides $\mathrm{REH}_{2+\mathrm{x}}$ with $\mathrm{x}=0.01-0.87$ and under-stoichiometric trihydrides $\mathrm{REH}_{3-\mathrm{y}}$ with $\mathrm{y}=0.01$ is reported [6], while the specific mechanisms of phase transformations depend on the type of the RE. The $\mathrm{REH}_{2}$ dihydrides are very stable, with reported formation enthalpies about $-200 \mathrm{~kJ} /$ $\mathrm{mol} \mathrm{H}_{2}$, and thus they decompose in vacuum releasing hydrogen and forming individual RE metals at very high temperatures only, with peaks of $\mathrm{H}_{2}$ desorption appearing between $925 \mathrm{~K}\left(\mathrm{CeH}_{2}\right)$ and $1073 \mathrm{~K}\left(\mathrm{LaH}_{2}\right)$. Experimental studies and theoretical modeling on the phase diagrams showed presence of two-phase equilibria $\mathrm{REH}_{3}$ $\leftrightarrow \mathrm{REH}_{2}$ and $\mathrm{REH}_{2} \leftrightarrow \mathrm{RE}$ and have been performed for several $\mathrm{RE}-\mathrm{H}$ systems, including Dy-H [7], Ho-H [8] and Er-H [9].

Despite a number of kinetic studies on hydrogenation of rare 
earth metals and decomposition of their hydrides has been published so far, these works containing only a few studies of the hydrides of "heavy" RE, including absorption of hydrogen by Ho [10] and hydrogen desorption from erbium hydride [11], were focused on the investigations of the kinetic properties in the metal hydride systems containing "heavy" RE while earlier performed studies of the desorption properties of the rare earth hydrides are limited to $\mathrm{Y}$ and $\mathrm{RE}=\mathrm{La}, \mathrm{Ce}, \mathrm{Pr}, \mathrm{Nd}, \mathrm{Sm}, \mathrm{Gd}, \mathrm{Tb}$ and $\operatorname{Er}[1,5]$.

The Thermal Desorption Spectroscopy (TDS) study together with characterization of the kinetics of metal-hydrogen interactions allows identifying possible mechanisms and ratecontrolling steps of hydrogen desorption [12] but unfortunately such studies have not been performed for the hydrides of heavy rare earth metals yet. A recently developed theoretical model of the hydrogen TDS process [13] is based on a simultaneous fitting of a series of individual TDS traces measured at variable constant rates of temperature changes which allows describing hydrogen thermal desorption traces by utilizing a modified Kissinger approach and a combined form of a differential kinetic equation. The method allows to accurately determine the activation energy of hydrogen desorption and pre-exponent factor of the desorption kinetic process, and together with three other semi-empirical parameters identifies the reaction mechanisms of phase-stuctural transformations.

The present work is focused on the studies of the kinetics and mechanism of hydrogen desorption from trihydrides of heavy rare earth metals, $\mathrm{DyH}_{3}, \mathrm{HoH}_{3}, \mathrm{ErH}_{3}$, by using a temperature programmed hydrogen desorption spectroscopy and kinetic analysis. Its aim is to apply the mathematical model developed in Ref. [13] to the chartacerisation of the experimental TDS data for three systems based on heavy RE, Dy- H, Ho-H and $\mathrm{Er}-\mathrm{H}$. These studies are essential as allowing to establish conditions for the HDDR process to optimize the synthesis of the nanostructured alloys and their hydrides as permanent magnets with increased energy product.

\section{Experimental}

\subsection{Synthesis of the initial $\mathrm{REH}_{3}$ trihydrides}

The samples of rare-earth metals (in each studied case the purity was higher than 99.7\%), 1-2 g each, were activated by heating up to $1073 \mathrm{~K}$ in vacuum at pressures lower than $1 \times 10^{-5} \mathrm{mbar}$, at a heating rate of $5 \mathrm{~K} \mathrm{~min}^{-1}$, followed by the furnace cooling after switching off the power. When the sample temperature decreased to $673 \mathrm{~K}$, the autoclave with the sample was filled with hydrogen gas with a pressure of 10-15 bar resulting in a quick hydrogen absorption to form a trihydride $\mathrm{REH}_{3}$. Hydrogenation was followed by a vacuum hydrogen desorption finishing at $1123 \mathrm{~K}$. Before studying the kinetics properties of the Re hydrides, the samples were cycled two times as specified above. During the absorption, RE metal absorbed 1.75-1.8 wt\% $\mathrm{H}$, which is higher than $95 \%$ of the theoretical $\mathrm{H}$ storage capacity corresponding to the formation of the trihydrides $\mathrm{REH}_{3}$ thus indicating completeness of the saturation of the samples with hydrogen.

\subsection{TDS characterization}

The TDS study was then performed at various heating rate setpoints ( $\beta$ in $T=T_{0}+\beta t$ ) in a range of $\beta=1-5.5 \mathrm{~K} \mathrm{~min}^{-1}$. The sample for the TDS experiment ( $300 \mathrm{mg}$ ) was loaded inside an Ar glove box into the autoclave made of a $1 / 2$ " SS316 tubing and equipped with a port for K-type thermocouple whose end was located approximately at $1 / 2$ of the height of the powdered sample. The thermal desorption spectra were measured at a constant heating rate in the temperature range from room temperature to $1173 \mathrm{~K}$ in vacuum (pressure for starting the measurements was $1 \times 10^{-5}$ mbar) provided by a turbomolecular pump.

During the gas evolution in the course of the TDS studies, the gas pressure at the entrance of the turbomolecular pump measured by Pirani-Penning vacuum sensor was between $3 \times 10^{-5}$ and $2 \times 10^{-2}$ mbar; thus the pressure drop related to the flow of the evacuated $\mathrm{H}_{2}$ can be considered to be equal to the readings of the vacuum sensor. Further calibration (see section "Volumetric measurements (TDS/re-hydrogenation)" in the supplementary information to Ref. [14] for the details) allowed to calculate $\mathrm{H}_{2}$ desorption flow $\left(\mathrm{Ncm}^{3} \mathrm{~min}^{-1} \mathrm{~g}^{-1}\right)$ from the measurements data of the Pirani-Penning sensor during the TDS experiments. The TDS measurements were performed in a sequence listed in Table 1 . The heating rate setpoints were chosen in a range between 1 and $5.5 \mathrm{~K}^{-1}$. During $\mathrm{H}_{2}$ desorption events these selected rates provided the readings within the specified in the paper measurement range of the vacuum sensor and were within the range used during its calibration. This allowed to accurately determine the amount of hydrogen released during the desorption experiments.

\section{Results and discussion}

\subsection{Modeling of the TDS spectra}

Kinetics of phase transformations in metal hydrides during hydrogen desorption is commonly described by a model of transformations in the solid-state using Eq. (1) [15,16, [21]]:

$\frac{d X}{d t}(T, t)=K_{T} \cdot f(X)$

Here $X$ is a reacted fraction which is a normalized amount of the phase transformed during the reaction time $t, d X / d t$ is a reaction rate, $f(X)$ is the rate dependence function (reaction model), $T$ is the temperature, and $K_{T}$ is a temperature-dependent rate constant. The temperature dependence of $K_{T}$ is expressed by the Arrhenius Equation:

$K_{T}=K_{o} \exp \left(-\frac{E_{A}}{R T}\right)$

Here $E_{A}$ is the apparent activation energy of the reaction, $K_{o}$ is a frequency factor, and $R=8.3144598 \mathrm{~J} \mathrm{~mol}^{-1} \mathrm{~K}^{-1}$ is the universal gas constant.

For the isothermal experiment, the determination of $K_{T}$ in Eq. (2) is straightforward. However, for the non-isothermal case, we assumed that a similar reaction mechanism is valid in all considered temperature range. In such a case $f(X), E_{A}$ and $K_{o}$ become temperature-independent.

Using the described principle, a standard approach for obtaining activation energy will require performing a series of experiments at various heating rates $\beta$ thus allowing to measure a temperature, $T_{m}$, at which the maximum reaction rate is observed (it is called the "peak temperature" later in the paper). Kissinger [17] showed that for the reaction of $n$th order, $f(X)=F_{n}(X)$, regardless of the value of $n$ :

Table 1

The heating rate set points $\left(\mathrm{K} \mathrm{min}^{-1}\right)$ during the dehydrogenation experiments.

\begin{tabular}{llllll}
\hline Series No & Sample & \multicolumn{4}{l}{ Experiment No } \\
\cline { 3 - 6 } & & 1st & 2nd & 3rd & 4th \\
\hline 1 & $\mathrm{DyH}_{3}$ & 2.5 & 1 & 4 & 5.5 \\
2 & $\mathrm{HoH}_{3}$ & 2.5 & 4 & 1 & 5.5 \\
3 & $\mathrm{ErH}_{3}$ & 5.5 & 1 & 4 & 2.5 \\
\hline
\end{tabular}


$\frac{d\left(\ln \left(\frac{\beta}{T_{m}^{2}}\right)\right)}{d\left(\frac{1}{T}\right)}=-\frac{E_{A}}{R}$,

or [18]:

$\ln \left(\frac{\beta}{T_{m}^{2}}\right)=\ln \left(\frac{K_{0} \cdot R}{E_{A}}\right)-\frac{E_{A}}{R \cdot T_{m}}$

Then, by plotting $y=\ln \left(\frac{\beta}{T_{m}^{2}}\right)$ versus $x=\frac{1}{T_{m}}$, the activation energy can be obtained as follows:

$y=A+B \cdot x$

$E_{A}=-B \cdot R ; \ln \left(K_{0}\right)=A+\ln (-B)$.

The modeling of the TDS data was carried out using a procedure described in our earlier publication [13]. The temperaturedependent reaction rates and reacted fractions were modelled using Eq. (5) where $X_{m}$ is the reacted fraction at a peak maximum $\left(T=T_{m}\right)$ :

$\frac{d X}{d t}(T, X)=K_{0} \exp \left(-\frac{E_{A}}{R T}\right) \cdot \frac{f(X)}{f\left(X_{m}\right)}$.

The specific type of function $f(X)$ (Eq (1) and (5)) depends on the mechanism controlling the rate of the reaction. Usually, these functions are derived analytically [16]. The general solution proposed by Šesták and Bergren [19] and developed further in Ref. [15], presents the equation for the rate dependence function as:

$f(X) \equiv \mathrm{G}_{M, N, P}(X)=X^{M}(1-X)^{N}[-\ln (1-X)]^{P}$

Various combinations of the values of the parameters $M, N$, and $P$ in Eq. (6) define reaction controlling mechanisms. In particular, a combination $M=P=0, N \geq 0$ corresponds to a phase boundary reaction with one-, two- and three-dimensional movement of the interface at $N=0,1 / 2$ and $2 / 3$, respectively. In turn, when $M=0$ and $N=1$, the reaction is controlled by the growth of nuclei $(P>0)$ or by diffusion $(P<0)$. Finally, the values $M>0$ imply that the ratelimiting step is nucleation.

Most frequently used analytically derived reaction models $[16,20,21,22]$ and their relation to the general representation of the rate dependence function, $G_{M, N, P}(X)$ (Eq. (6)) $[13,19]$, are presented in the Supplementary Information file, Table S1 and Fig. S1. Specific values adopted by three parameters, $M, N$, and $P$, identify a kinetic model describing a considered transformation.

\subsection{Models of the kinetic processes on the RE-H systems}

The main mechanisms successfully describing phase-structural transformations in the metal-hydroden systems based on application of the general Avraami approach include:

- Nucleation and Growth (NG);

- Phase-Boundary Reaction (PB) and

- Hydrogen Diffusion $\left(\mathbf{D}^{1}\right)$.

\footnotetext{
${ }^{1}$ Diffusion as a rate controlling step in the transformation is described by several analytical models $[16,20]$. However, it appears that they all can be well approximated by the Avraami nucleation and growth model $\mathrm{A}_{n}$ with $n<1$ [22].
}

The corresponding rate dependence functions of transformations and modelled TDS spectra are presented in Fig. 1a and $b$, respectively.

As it can be seen from Fig. 1a, for the various transformation mechanisms the dependences of $f(X)$ from the reacted fraction $X$ presented as graphs show very different shapes.

Three cases described by the Nucleation and Growth mechanism include:

(a) Standard Kissinger type dependence [17] which is described by the first-order reaction, $\mathrm{F}_{1}\left(\mathrm{~A}_{1}\right)$; in such a case when $X$ changes from 0 to $1, f(X)$ linearly decreases from 1 to 0 . The mechanism of the transformation belongs to the nucleation and growth type one and we denote it as NG1 (as there are other NG type transformations which differ from each other by the values of the coefficient $P$ ).

(b) Another transformation which obeys the NG mechanism and is denoted as NG2 in Fig. 1a, is described by a graph having a negative curvature in the whole range of $X$ and reaching a maximum of $f(X)$ at $0<X<1 f(X)$ while $f(X)$ is equal to zero at $X=0$ and $X=1$.

(c) Finally, the NG3 case describes a mixed nucleation and growth mechanism which is rate-limited by the nucleation at
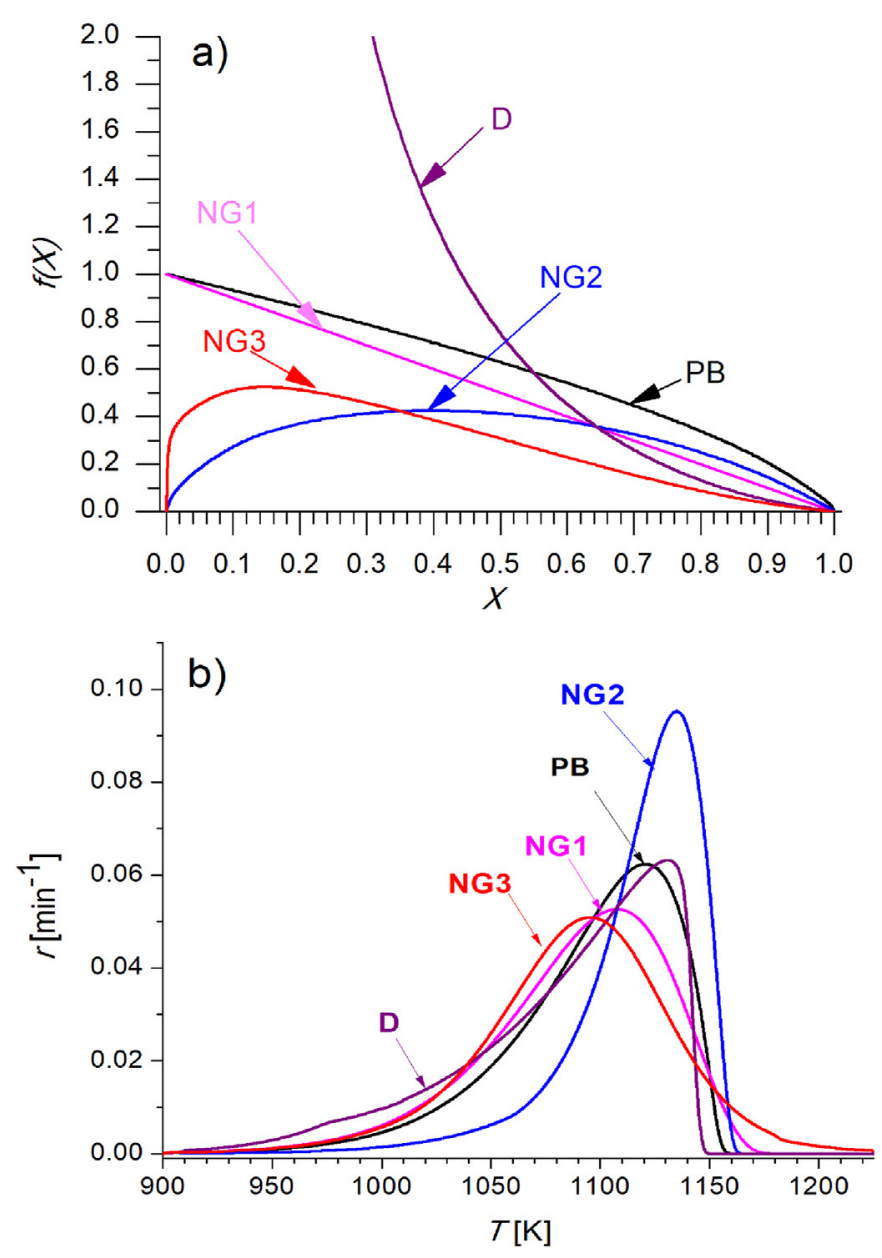

Fig. 1. a- Examples of the rate-dependence functions corresponding to the typically observed reaction mechanisms (Table 2); b- modelled thermal desorption spectra (Eq. (1)) for the heating rate of $5 \mathrm{~K} \mathrm{~min}^{-1}$ calculated assuming $\ln \left(\mathrm{K}_{0}\right)=24.7, \mathrm{E}_{\mathrm{A}}=255 \mathrm{~kJ} /$ $\mathrm{mol}, \mathrm{X}_{\mathrm{m}}=0.6$. Similar graphs representing various reaction models are presented in the Supplementary Information (Fig. S1). The influence of the effects of variations in $\mathrm{K}_{0}, \mathrm{E}_{\mathrm{A}}$ and $\mathrm{X}_{\mathrm{m}}$ is shown in Fig. S2. 
Table 2

Typical reaction mechanisms as related to their corresponding reaction models.

\begin{tabular}{|c|c|c|c|c|c|c|}
\hline \multirow[t]{2}{*}{ Mechanism } & \multirow[t]{2}{*}{ Notation } & \multirow[t]{2}{*}{ Reaction model ${ }^{\mathrm{a}}$} & \multicolumn{4}{|c|}{ Parameters in Eq. 6} \\
\hline & & & $M$ & $N$ & $P$ & Relation \\
\hline Diffusion & D & $A_{0.67}$ & 0 & 1 & -0.5 & $\mathrm{G}_{0,1,-1}=1.5 A_{0.67}$ \\
\hline Phase Boundary Reaction & PB & $\mathrm{R}_{3}$ & 0 & $2 / 3$ & 0 & $\mathrm{G}_{0,2 / 3,0}=\mathrm{R}_{3} / 3$ \\
\hline \multirow[t]{3}{*}{ Nucleation and Growth } & NG1 ${ }^{\mathrm{b}}$ & $\mathrm{A}_{1}=\mathrm{F}_{1}$ & 0 & 1 & 0 & $\mathrm{G}_{0,1,0}=A_{1}$ \\
\hline & NG2 ${ }^{\mathrm{c}}$ & $\mathrm{A}_{2}$ & 0 & 1 & 0.5 & $\mathrm{G}_{0,1,0.5}=\mathrm{A}_{2} / 2$ \\
\hline & $\mathbf{N G 3}^{\mathrm{d}}$ & $\mathrm{B}_{0.2,1.5}$ & 0.2 & 1.5 & 0 & $\mathrm{G}_{0.2,1.5,0}=\mathrm{B}_{0.2,1.5}$ \\
\hline
\end{tabular}

\footnotetext{
a See Supplementary information, Table S1.

b Grain boundary nucleation or geometry specified diffusion.

c Instant nucleation is followed by a 2D-growth while all values of $P>0$ at $M=0$ and $N=1$ are assumed to correspond to the NG2 mechanism.

d Nucleation according to the power law $(M>0)$; diffusion-limited growth $(N>1)$.
}

the beginning of the transformation and the diffusion at later stages. As can be seem from Fig. 1 a, $f(X)$ curve becomes deformed as compared to NG2, with a maximum shifted towards the lower reacted fractions followed by inflection of the graph which becomes concave at $X \rightarrow 1$, as is characteristic for the diffusion mechanism.

A monotonous decrease of $f(X)$ from 1 to 0 when $X=0 \ldots 1$ is also characteristic for the Phase-Boundary (PB) Reaction mechanism. However in this case the graph shown in Fig. 1a is convex with a negative curvature. Finally, for the reaction completely controlled by the diffusion $(\mathbf{D}), f(X)$ rapidly changes from very high values at $X \rightarrow 0$ to zero when $X \rightarrow 1$, while the positive curvature (concave graph) is observed in the whole range of $X$.

Various parameters $M, N, P$ describing these typical mechanisms are presented in Table 2. We note that general NG mechanism includes several specific types which are related to the mechanism of nucleation and a dimensionality of growth, further to the case of the rate limited by diffusion. Accordingly, the NG mechanisms presented in Table 2, NG1 and NG2, are described by reaction models $A_{n}$ (see Table S1) characterized by different values of the parameter $n$, while NG3 represents a branching nuclei interacting model $\left(\mathrm{B}_{m, n}\right.$ in Table S1) with $m>0$ and $n>1$. A more detailed discussion is presented in Section 3.5 below.

Most importantly, the different reaction mechanisms corresponding to different combinations of the parameters $M, N$ and $P$ also influence the shape of the TDS peak as is clear from the TDS curves shown in Fig. 1b.

For all mechanisms, the peaks appear to be asymmetric and show a steep descending branch after reaching the peak maximum. The highest asymmetry of the TDS curve is observed for the ratelimiting diffusion (D) characterized by a slow increase of the reaction rate before the peak maximum followed by its rapid decline. Similar in shape but a less pronounced peak asymmetry is observed for the NG mechanism at high values of $P$ parameter $\left(n>1\right.$ in the $A_{n}$ model, see the curve for NG2/ $/ A_{2}$ ). In this case, the rate increase before reaching a peak maximum ${ }^{2}$ observed at the same temperature as for $\mathbf{D}$ is lower, with a similar rapid rate descent of the TDS curve after passing the peak maximum.

The decrease of $P$ parameter results in broadening of the peak, with higher reaction rate observed at the ascending branch and lower peak value reached at lower temperatures; the maximum is followed by a less rapid decrease in the rate (NG1).

A contribution of nucleation $(M>0)$ and diffusion $(N>1)$ in the NG mechanism intensifies the latter trend making the peak to adopt almost symmetrical shape (NG3).

\footnotetext{
${ }^{2}$ We note that the areas of all the TDS peaks (Fig 1b, S1, S2) calculated assuming the equal constant heating rate are equal.
}

Finally, the peak shape for $\mathbf{P B}$ mechanism is similar to the $\mathbf{D}$ one, with a slightly faster rates before reaching the peak maximum.

As it can be seen from the analysis of the experimental data presented for the decomposition of $\mathrm{MgH}_{2}$ in Ref. [13], fitting of the TDS peaks using the model [13] allows deriving the kinetic parameters of dehydrogenation by processing a set of the experimental thermal desorption spectra measured at different heating rates. As a result of the fitting of the experimental TDS data with Eqs (5) and (6), aimed at achieving the best agreement between the calculated and observed TDS traces, the fitted values of $K_{0}$ and $E_{A}$ (Eq. (5)) will be obtained and will provide important quantitative information concerning the dehydrogenation kinetics, while a combination of the fitted parameters $M, N$ and $P$ (Eq. (6)) allows to identify a possible mechanism of hydride decomposition.

Further details on the TDS modelling procedure applied in this work are presented in the Supplementary Information, Sections 1 and 2.

We note that due to unknown a priori reaction mechanism and, therefore, impossibility of the selection of "allowed" values of the parameters $M, N$ and $P$, during the performed in the present study refinements, these parameters were allowed to vary during the fitting, with starting assumpptions $M=0, N=1$ and $P=0^{3}$ which defines the first order reaction model $F_{1}\left(A_{1}\right)$; see Table 2 . The deviations of the fitted values of $M, N$ and $P$ from the "allowed" combinations are belived to originate from the realization of the mixed mechanisms (see Section 3.5 below)

\subsection{Hydrogen desorption from $\mathrm{REH}_{3}$ hydrides studied by Thermal Desorption Spectrosopy}

Fig. 2 shows the measured hydrogen thermal desorption spectra of $\mathrm{REH}_{3}$, where $\mathrm{RE}=\mathrm{Dy}(\mathrm{a})$, Ho (b), and $\mathrm{Er}$ (c). The spectra contain two main peaks, which will be analyzed and modelled in the present study.

The first main peak corresponds to the desorption of hydrogen during the phase transformation $\mathrm{REH}_{3} \rightarrow \mathrm{REH}_{2}$, which occurs in the range $443-513 \mathrm{~K}$ while the second main peak ranges from 1023 to $1173 \mathrm{~K}$ and is associated with complete desorption of hydrogen from $\mathrm{REH}_{2}$ to yield initial rare earth metals RE.

Fig. 3 shows the temperatures of the first (a) and the second (b) main hydrogen desorption peaks as a function of the heating rate. The corresponding literature data [5] for $\mathrm{RE}=\mathrm{Y}, \mathrm{Ce}, \mathrm{Pr}, \mathrm{Nd}, \mathrm{Sm}, \mathrm{Gd}$, $\mathrm{Tb}$ taken at the heating rate of $5 \mathrm{~K} \mathrm{~min}^{-1}$ are presented in Fig. 3 as well.

It can be seen from Fig. 3a that the stability of the studied trihydrides is similar to the trihydrides of "heavy" RE (Y, Sm, Gd, Tb)

\footnotetext{
${ }^{3}$ The details of the fitting procedure for the parameters $M, N$ and $P$ are described in Supplementary Information, Section 2.
} 

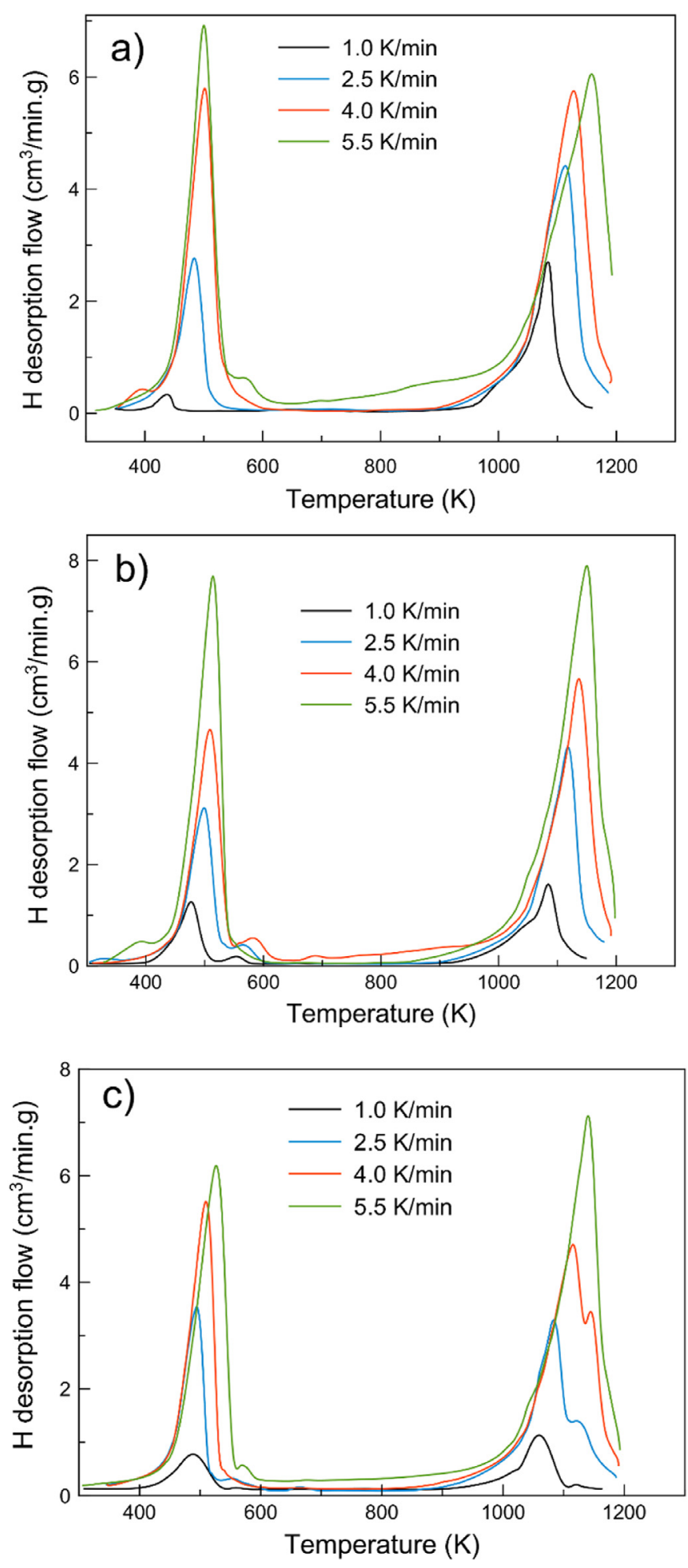

Fig. 2. TDS traces for $\mathrm{REH}_{3}$ hydrides: $\mathrm{DyH}_{3}$ (a), $\mathrm{HoH}_{3}$ (a) and $\mathrm{ErH}_{3}$ (c).

and is significantly lower than the stability of the trihydrides of "light" RE (Ce, Nd, Pr). The stability of the studied trihydrides shows a trend to increase in the series $\mathrm{DyH}_{3}<\mathrm{HoH}_{3}<\mathrm{ErH}_{3}$ correlating with the increase of the RE atomic number in the Periodic Table.

In contrast, decomposition of the dihydrides (Fig. 3b) is characterized by an opposite trend: thermal stability of the studied $\mathrm{REH}_{2}$ is significantly higher than the one for both "light" (Ce-Pr)
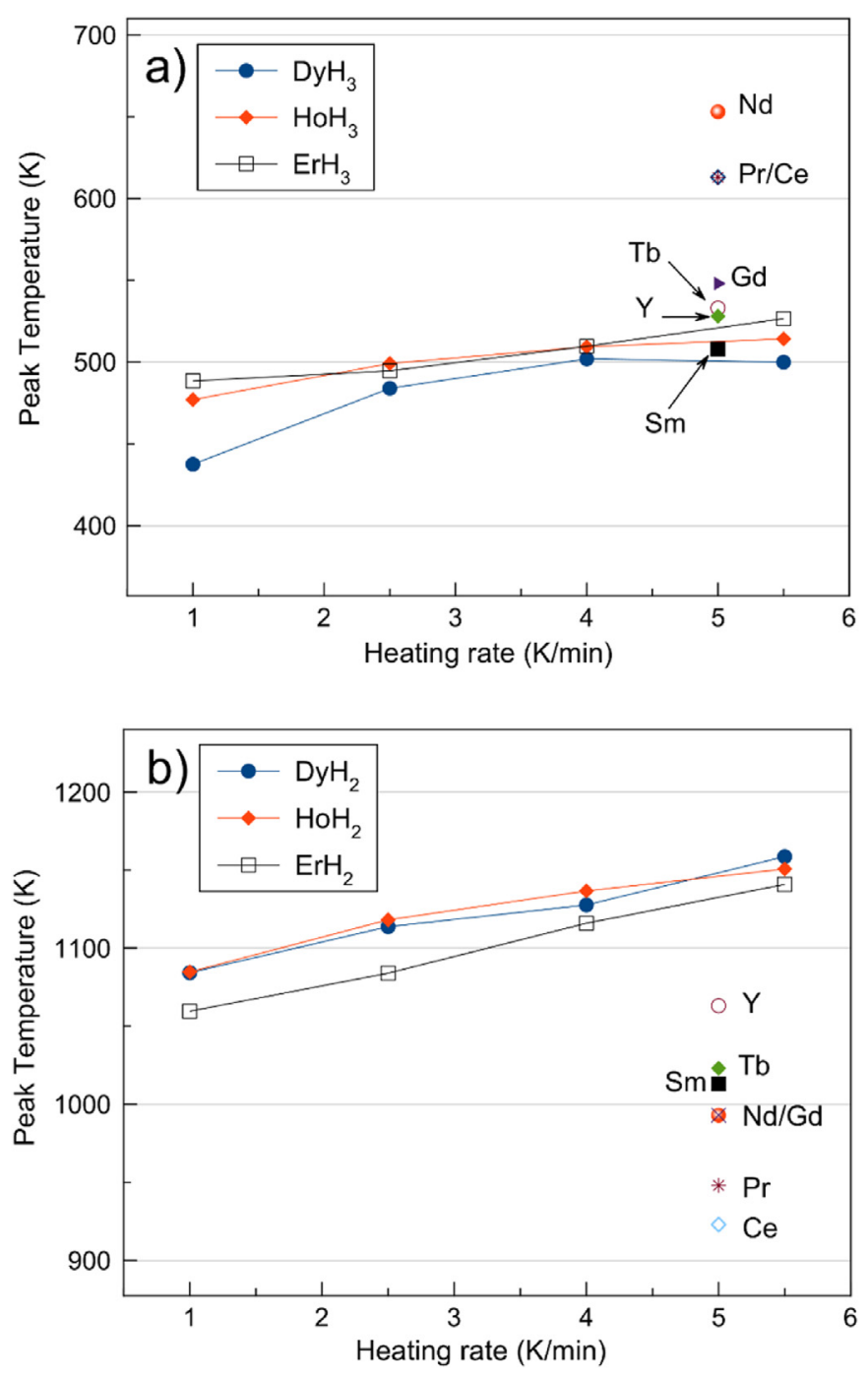

Fig. 3. Peak temperatures for hydrogen desorption from the TDS data for the experiment at several heating rates: a) The 1 st peak $\left(\mathrm{ReH}_{3}-\mathrm{RH}_{2}\right)$. b) The 2 nd peak $\left(\mathrm{ReH}_{2}-\mathrm{RH}_{0}\right)$. Data for several $\mathrm{REH}_{2-3}$ hydrides from previously published paper [5] are also included in the plot.

and "heavy" (Y, Sm, Gd, Tb) RE studied in Ref. [5], exhibiting a tendency to decrease with the increase of the RE number in the Periodic Table: $\mathrm{ErH}_{2}<\mathrm{HoH}_{2}<\mathrm{DyH}_{2}$.

To get a better understanding of the process of hydride decomposition, a hydrogen desorption curve from $\mathrm{DyH}_{3}$ (Fig. 2a) measured at a heating rate of $4 \mathrm{~K} \mathrm{~min}^{-1}$ was overlaid with the Dy-H phase diagram, see Fig. 4 . It can be seen that the $\mathrm{REH}_{3}$ hydride transforms into the RE metal in several steps which correspond to two main stages of hydrogen desorption, i.e. stage $A$ is related to the first peak, while the stage $B$ is related to the second peak of hydrogen desorption:

$\gamma \mathrm{REH}_{3-y} \stackrel{A}{\rightarrow} \beta \mathrm{REH}_{2-x} \stackrel{B}{\rightarrow} \alpha R E H$

The peak temperatures of hydrogen desorption clearly depend on the heating rate and shift to the higher temperatures following the rate of the temperature increase. The peak temperatures slightly change between Dy, Ho, and Er hydrides and one can note that the trends vary between the trihydrides $\mathrm{REH}_{3}$ and dihydrides $\mathrm{REH}_{2}$. As an example, $\mathrm{ErH}_{3}$ shows the peak at a slightly lower temperature as compared to $\mathrm{DyH}_{3}$ and $\mathrm{HoH}_{3}$, while the peak for 


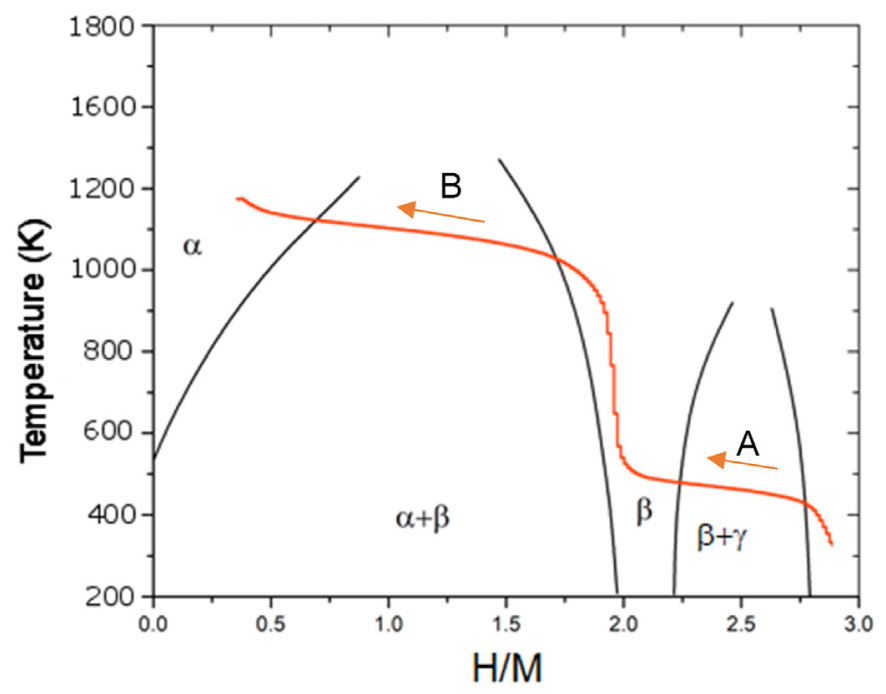

Fig. 4. Hydrogen desorption traces from $\mathrm{DyH}_{3}$ (red) overlaid on the phase diagram of $\mathrm{Dy}-\mathrm{H}$. Arrows indicate the path of desorption. (For interpretation of the references to colour in this figure legend, the reader is referred to the Web version of this article.)

$\mathrm{ErH}_{2}$ is observed at a higher temperature as compared to $\mathrm{DyH}_{2}$ and at a slightly lower temperature as compared to $\mathrm{HoH}_{2}$ (see Table 3 for the details).

Reported in the literature enthalpies of formation of $\mathrm{REH}_{2}$ vary from $-224 \pm 12 \mathrm{~kJ} / \mathrm{mol}$ for $\mathrm{ErH}_{2},-213$ to -220 for $\mathrm{DyH}_{2}[7,23]$ and $-219 \pm 12 \mathrm{~kJ} / \mathrm{mol}$ for $\mathrm{HoH}_{2}$ [8]. It can be seen that the enthalpies of formation for these three RE dihydrides have very close values and thus well agree with the similar values of peak temperatures from TDS studies when the data were collected in the same regimes.

\subsection{Kissinger analysis}

The kinetic parameters derived from the fitting of the experimental data provided by the Kissinger analysis of TDS traces for the studied RE hydrides are listed in Table 3. The corresponding Kissinger plots are shown in Fig. 5.

From Fig. 5 it can be deduced that for all three studied hydrides both transformations, $\mathrm{REH}_{3} \rightarrow \mathrm{REH}_{2}$ (low-temperature Peak 1(a)) and $\mathrm{REH}_{2} \rightarrow \mathrm{RE}$ (high-temperature Peak 2(b)) are described by linear dependences of $\ln \left(\frac{\beta}{T_{m}^{2}}\right)$ vs $1 / T$ which is in agreement with Kissinger approach ${ }^{4}$.

From the data presented in Table 3 we conclude that

(a) Activation energy of the transformation $\mathrm{REH}_{3} \rightarrow \mathrm{REH}_{2}$ (Peak 1), 36-78 kJ/mol $\mathrm{H}_{2}$, is significantly lower than for the Peak 2 $-\mathrm{REH}_{2} \rightarrow \mathrm{RE}, 187-256 \mathrm{~kJ} / \mathrm{mol} \mathrm{H}_{2}$;

(b) The activation energy of phase transformations $\mathrm{REH}_{2} \rightarrow \mathrm{RE}$ is the lowest for the Er-based hydride and the highest for the Ho-based hydride.

(c) The activation energy of phase transformations $\mathrm{REH}_{3} \rightarrow \mathrm{REH}_{2}$ is the lowest for Dy-based hydrides and the highest for Hobased hydrides.

For the 1st peak, the apparent activation energy for hydrogen

\footnotetext{
${ }^{4}$ Deviations from the linearity (Fig. 5) are caused by the deviations of the heating rate from the setpoint during the experiment.
}

desorption from $\mathrm{REH}_{3}$ shows a trend of $\mathrm{DyH}_{3} \approx \mathrm{ErH}_{3}<\mathrm{HoH}_{3}$. The trend is quite different for the hydrogen desorption from the $\mathrm{REH}_{2}$ in which $\mathrm{ErH}_{2}$ has the smallest activation energy with an overall trend of $\mathrm{ErH}_{2}<\mathrm{DyH}_{2}<\mathrm{HoH}_{2}$.

\subsection{Mechanism of hydrogen desorption}

Table 4 presents fitted parameters of the experimental TDS traces calculated from the simulated TDS spectra. The experimental TDS curves and their fitting results are presented in the Supplementary Information, Fig. S3 $\left(\mathrm{DyH}_{3}\right), \mathrm{S} 5\left(\mathrm{HoH}_{3}\right)$ and $\mathrm{S} 7\left(\mathrm{ErH}_{3}\right)$. As can be seen from Fig. 6 presenting typical TDS data $\left(\mathrm{ErH}_{3}\right)$, the fitting results show a good agreement between the experimental and calculated spectra.

However, one can note that the fit becomes less successful for the Peak 2. The reasons for that may include

(i) higher deviations from the linear heating at the last stages of the data collection at the highest temperatures and

(ii) possible changes of the mechanism during decomposition of $\mathrm{REH}_{2}$ which result in the distortion of the peak shape (see the curves for 2.6 and $4.4 \mathrm{~K} \mathrm{~min}^{-1}$ in Fig. 6). It appears that the second peak, in fact, can be deconvoluted into two overlapping peaks. Such a behaviour is related to the mechanism of the phase-structural transformations at high temperatures and requires further studies.

Various mechanisms of transformations were identified in the studied hydride systems. These mechanisms are manifested by different combinations of the fitted values of $M, N$, and $P$ (see Table 4), as well as by different shapes of the $f(X)$ curves (see Fig. 7) calculated according to Eq. (5). The value of $P$ refined at the fixed values $M=0$ and $N=1$ (see Supplementary Information, section 2), brings a very useful data about the basic mechanism of the transformations since it yields the value of $n$ in the Avraami - Erofeev model $A_{n}$ (see Table 2) as:

$n=\frac{1}{1-P}$.

When $n>1(P>0)$, the basic mechanism unambigously involves nucleation and growth (NG) which may be characterized by different nucleation mechanisms, growth dimensionalities and includes a possible contribution of diffusion as related to the value of $n$ [22,24-27].

The value $n<1(P<0)$ points at the basic mechanism related to diffusion (D) while the value $n=1(P=0)$ can be interpreted both as nucleation and growth (NG1) and phase boundary reaction (PB) mechanisms (see Table 2).

The NG2 with random nucleation and 3D-growth has been identified as a basic mechanism for the $\mathrm{DyH}_{3} \rightarrow \mathrm{DyH}_{2}$ (Fig. 7a) transformation. In this case the $f(X)$ curve shows the presence of a pronounced maximum at $X \sim 0.4$. At the fixed values $M=0$ and $N=1$ the value of $P$ was refined to appr. 0.75 which corresponds to Avraami exponent equal to 4 (Eq. (7)) unambiguously confirming this mechanism. ${ }^{5}$ The value $M>0$ obtained during further

\footnotetext{
5 According to Ref. [24,25] the Avraami exponent, $n$, can be presented as a sum, $n=n_{g}+n_{n}$, where $n_{g}$ is growth dimensionality and $n_{n}$ is related to the nucleation mechanism. When $n_{n}=1$, the nucleation takes place randomly, and $n_{n}=0$ corresponds to the instant nucleation, so as $n=n_{g}$. Thus $n=4$ corresponds to the random nucleation followed by 3D-growth. The values $n<4$ correspond to non-random nucleation taking place at points $(n=3)$, edges $(n=2)$, or at surfaces $(n=1)$ [27]. The non-integer values of $n$ can be associated with the change of the nucleation mechanism during the reaction [25] and/or contribution from $\mathrm{H}$ diffusion $[22,26]$.
} 
Table 3

TDS parameters derived by the initial processing of the experimental datasets.

\begin{tabular}{|c|c|c|c|c|c|c|c|c|c|c|c|c|c|c|c|}
\hline \multirow[t]{2}{*}{ Hydride } & \multirow{2}{*}{$\begin{array}{l}\text { TDS \# ( } \beta \text { setpoint }(K \\
\left.\min ^{-1}\right)\end{array}$} & \multicolumn{7}{|c|}{ Peak \#1 } & \multicolumn{7}{|c|}{ Peak \#2 } \\
\hline & & $T_{i}(\mathrm{~K})$ & $\begin{array}{l}T_{m} \\
(\mathrm{~K})\end{array}$ & $\begin{array}{l}\beta(\mathrm{K} \\
\left.\min ^{-1}\right)\end{array}$ & $X_{m}$ & $\begin{array}{l}\ln \left(K_{0}\right. \\
\left.\left(\min ^{-1}\right)\right)\end{array}$ & $\begin{array}{l}E_{A}(\mathrm{~kJ} \\
\left.\mathrm{mol}^{-1}\right)\end{array}$ & $R^{2}$ & $T_{i}(\mathrm{~K})$ & $T_{m}(\mathrm{~K})$ & $\begin{array}{l}\beta(\mathrm{K} \\
\left.\min ^{-1}\right)\end{array}$ & $X_{m}$ & $\begin{array}{l}\ln \left(K_{0}\right. \\
\left.\left(\min ^{-1}\right)\right)\end{array}$ & $\begin{array}{l}E_{A}(\mathrm{~kJ} \\
\left.\mathrm{mol}^{-1}\right)\end{array}$ & $R^{2}$ \\
\hline \multirow[t]{4}{*}{$\mathrm{DyH}_{3}$} & $1(2.5)$ & 398.3 & 483.9 & 2.98 & 0.61 & $6.2 \pm 1.4$ & \multirow[t]{4}{*}{$36.2 \pm 5.5$} & \multirow[t]{4}{*}{0.9321} & 880.5 & 1113.7 & 2.58 & 0.68 & \multirow{4}{*}{$21.4 \pm 4.7$} & \multirow[t]{4}{*}{$226 \pm 43$} & \multirow[t]{4}{*}{0.8961} \\
\hline & $2(1)$ & 423.4 & 437.5 & 1.10 & 0.61 & & & & 883.5 & 1084.2 & 1.01 & 0.66 & & & \\
\hline & $3(4)$ & 370.2 & 501.9 & 4.69 & 0.61 & & & & 808.7 & 1127.6 & 4.06 & 0.69 & & & \\
\hline & $4(5.5)$ & 379.1 & 499.9 & 5.71 & 0.54 & & & & 739.8 & 1158.6 & 5.59 & 0.80 & & & \\
\hline \multirow[t]{4}{*}{$\mathrm{HoH}_{3}$} & $1(2.5)$ & 410.9 & 499.1 & 2.77 & 0.59 & $16.5 \pm 2.3$ & \multirow[t]{4}{*}{$77.9 \pm 9.4$} & \multirow[t]{4}{*}{0.9575} & 927.0 & 1118.1 & 2.45 & 0.71 & \multirow{4}{*}{$24.7 \pm 0.7$} & \multirow[t]{4}{*}{$256 \pm 6$} & \multirow[t]{4}{*}{0.9982} \\
\hline & $2(4)$ & 413.2 & 509.3 & 3.71 & 0.56 & & & & 725.0 & 1136.6 & 4.08 & 0.72 & & & \\
\hline & $3(1)$ & 425.3 & 477.0 & 1.09 & 0.56 & & & & 905.8 & 1084.7 & 0.98 & 0.60 & & & \\
\hline & $4(5.5)$ & 356.1 & 514.1 & 5.84 & 0.67 & & & & 915.8 & 1150.7 & 5.49 & 0.76 & & & \\
\hline \multirow[t]{4}{*}{$\mathrm{ErH}_{3}$} & $1(5.5)$ & 386.4 & 526.2 & 5.82 & 0.63 & $6.2 \pm 0.5$ & \multirow[t]{4}{*}{$37.7 \pm 2.2$} & \multirow{4}{*}{0.9930} & 729.7 & 1140.8 & 5.61 & 0.63 & \multirow{4}{*}{$17.5 \pm 4.0$} & \multirow[t]{4}{*}{$187 \pm 36$} & \multirow[t]{4}{*}{0.8952} \\
\hline & $2(1)^{a}$ & 414.3 & 488.4 & 1.09 & 0.56 & & & & 900.5 & 1059.5 & 1.00 & 0.58 & & & \\
\hline & $3(4)$ & 366.7 & 509.6 & 4.01 & 0.63 & & & & 890.8 & 1115.9 & 4.06 & 0.54 & & & \\
\hline & $5(2.5)$ & 352.2 & 494.6 & 2.97 & 0.64 & & & & 911.5 & 1083.9 & 2.54 & 0.49 & & & \\
\hline
\end{tabular}

a Not used in the Kissinger analysis for Peak \#1.
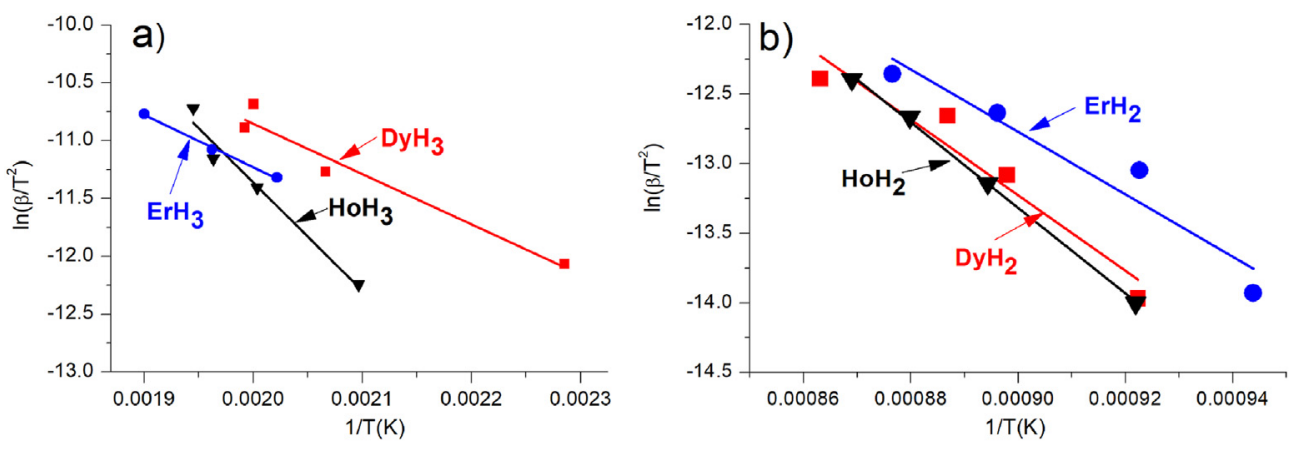

Fig. 5. Kissinger plots for the peaks \#\# 1 (a) and 2 (b).

refinement can be related to the nucleation taking place according to the power-law which controls the reaction at the beginning of the decomposition process [19]. The fitted value $N>1$ at the small positive value of $M$ also indicates a limitation of the nuclei growth by the diffusion [19]; this effect is manifested by a positive curvature of $f(X)$ graphs at $X>0.9$. Using the classification presented in Table 2, the mechanism of the $\mathrm{DyH}_{3} \rightarrow \mathrm{DyH}_{2}$ transformation was identified as NG2 + NG3.

When is comes to the transformation $\mathrm{DyH}_{2} \rightarrow \mathrm{DyH}_{0}$ (Fig. 7b), $f(X)$ is also characterized by a maximum at $X \sim 0.4$, hovewer, with the lower fitted values of $P$. The values of Avraami exponents of 1 and 1.5 (when $M=0$ and $N=1$ ) with $P$ being close to 0.33 , indicate significant limitations in the initiation of the nucleation areas and a decrease in the dimensionality of the growth $[13,19]$. As the fitted $N$ values are higher than 1 , this indicates a lower contribution of the diffusion into the NG2+NG3 mechanism for the $\mathrm{DyH}_{2} \rightarrow$ Dy transformation as compared to the $\mathrm{DyH}_{3} \rightarrow \mathrm{DyH}_{2}$ one.

The calculated rate-dependence functions for the transformation $\mathrm{HoH}_{3} \rightarrow \mathrm{HoH}_{2}$ (Fig. 7c) and $\mathrm{HoH}_{2} \rightarrow \mathrm{HoH}_{0}$ (Fig. 7d) significantly differ from the ones for the dysprosium hydrides. The observed maxima are much less pronounced and are shifted towards the lower $X$ values, close to the $X_{0}$. The refined values of $P$ (0.1-0.17; see Table 4) correspond to Avraami exponent between 1.11 and 1.20 indicating a significant decrease in the contribution of nucleation process for Peak 1 as compared to $\mathrm{DyH}_{3} \rightarrow \mathrm{DyH}_{2}$ transformation [19]. At $X>0.2$ the behaviour of $f(X)$ for $\mathrm{HoH}_{3} \rightarrow \mathrm{HoH}_{2}$ is close to the PB mechanism. However, as the values of $N$ are higher than $2 / 3$ (specific for a 3D movement of interface at a constant velocity $[16,20])$ we conclude that the transformation continues obeying the nucleation and growth mechanism with almost instant nucleation and a certain contribution from the diffusion (NG1).
Similar to the observations for $\mathrm{DyH}_{3}$, the value $N>1$ indicates a possible limitation of the diffusion on the nuclei growth [19] (NG3). The rate dependence function for the transformation $\mathrm{HoH}_{2} \rightarrow \mathrm{HoH}_{0}$ (see Fig. 7d); exhibits maximum only for the first dehydrogenation (heating rate $2.6 \mathrm{~K} / \mathrm{min}$ ). The refinement of all other spectra yields $M \sim 0, N \sim 1$ and $P \sim 0$ (Table 4) that indicates a first-order reaction (NG1 mechanism, see Table 2). According to Ref. [22], it corresponds to the nucleation and growth mechanism with either grain boundary nucleation or with a geometry specified diffusion as a rate-limiting step of the transformation.

The transformation $\mathrm{ErH}_{3} \rightarrow \mathrm{ErH}_{2}$ (Fig. 7e) exhibits a behaviour similar to the transformation $\mathrm{DyH}_{2} \rightarrow \mathrm{DyH}_{0}$. The combination of fitting parameters $M \sim 0, N \sim 1$ and $P=0.1-0.34$ (see Table 4) corresponds to the NG2 mechanism with Avraami exponent between 1 and 1.5. Similar to $\mathrm{DyH}_{2} \rightarrow \mathrm{DyH}_{0}$ transition, it corresponds to the limitations in the initiation of the nucleation areas and the decrease in the dimensionality of growth.

A similar behaviour, but with a more pronounced maximum of $f(X)$, is observed for $\mathrm{ErH}_{2} \rightarrow \mathrm{ErH}_{0}$ (Fig. 7f). The fitted values of $M$ and $N$ were close to zero and one, respectively, at $P=0.27-0.44$ corresponding to the NG2 mechanism with Avraami exponent between 1.4 and 1.8. An exception was the TDS\#4 taken at $2.5 \mathrm{~K} \mathrm{~min}^{-1}$ and characterized by the fitting parameters $M \sim 0.1, N \sim 1.7, P=0.41$ corresponding to the nucleation-controlled reaction at the beginning of the process and diffusion limitation of the nuclei growth [19] (NG2 + NG3).

Based on the modelling of the kinetic data presented above, the identified desorption mechanisms for each desorption stage are summarized in Table 5. For $\mathrm{DyH}_{3}$ and $\mathrm{ErH}_{3}$ the hydrogen desorption occurs according to the nucleation and growth mechanism (NG2 or NG2+NG3). However, the mechanisn becomes different for $\mathrm{HoH}_{3}$ 


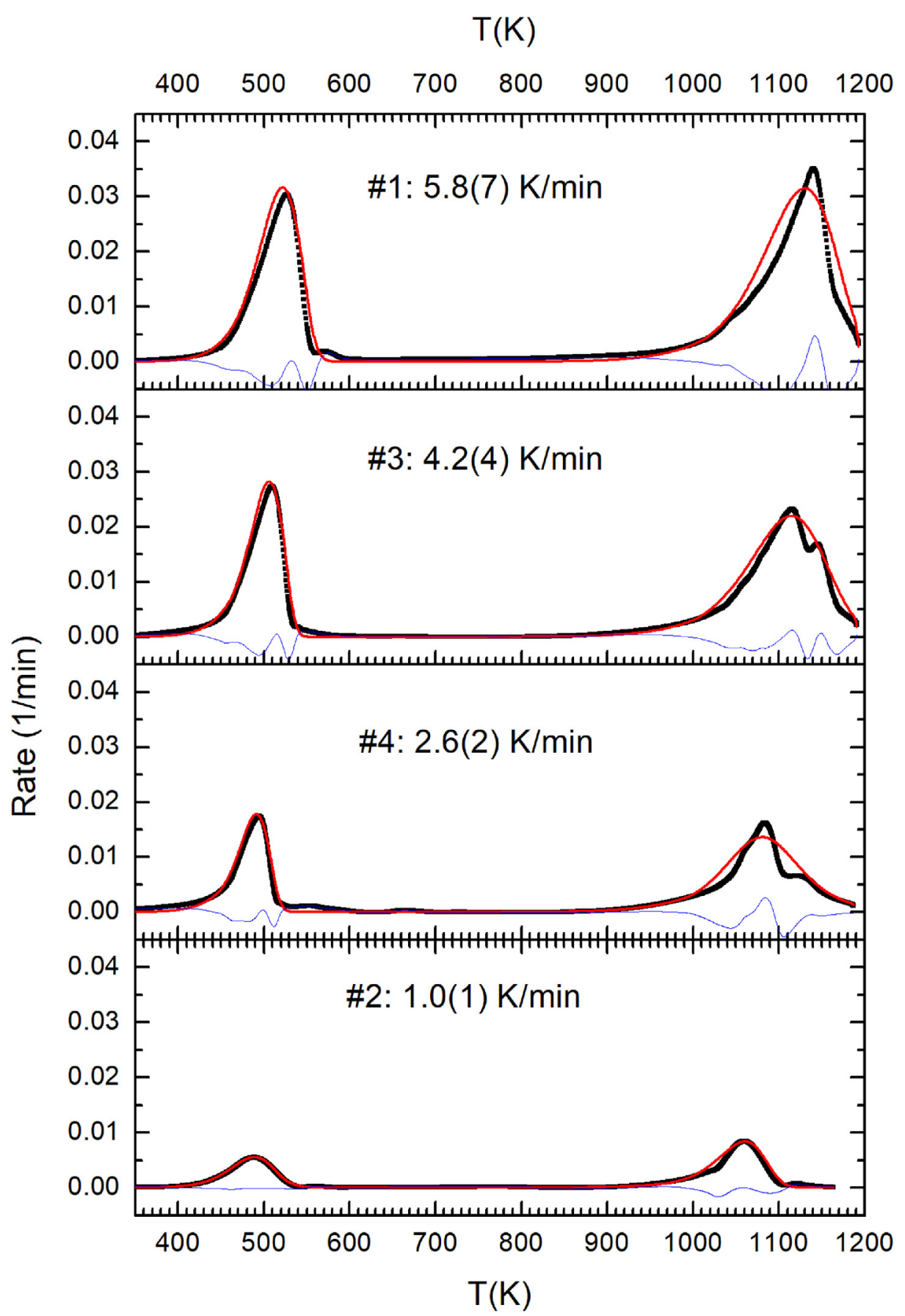

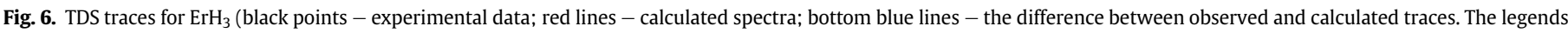

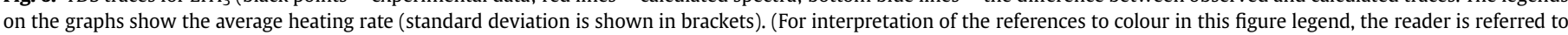
the Web version of this article.)

in which the desorption is desribed either by an instant nucleation followed by a diffusion-controlled growth (NG1), or by a phase boundary reaction $(\mathbf{P B})$.

For all the samples, the fitted values of the pre-exponent and the activation energy for both transformation events (Table 4) slightly deviate from the values determined by the Kissinger method (Table 3). For dysprosium and erbium hydrides, both $K_{0}$ and $E_{A}$ exhibit a trend of a slight decrease with dehydrogenation - rehydrogenation cycling. Importnatly, for $\mathrm{ErH}_{2} \rightarrow \mathrm{ErH}_{0}$ the fitted values of $E_{A}=165.5-182.4 \mathrm{~kJ} \mathrm{~mol}^{-1}$ are in good agreement with the data reported for $\mathrm{H}_{2}$ desorption for $\mathrm{ErH}_{2}: E_{A}=184 \pm 20 \mathrm{~kJ} \mathrm{~mol}^{-1}$ using complex and time consuming data collection [11].

\section{Conclusions}

The observed TDS behaviour is similar for $\mathrm{DyH}_{3}, \mathrm{HoH}_{3}$, and $\mathrm{ErH}_{3}$ trihydrides, all exhibiting two main peaks of hydrogen desorption. The first peak observed in the temperature range between 446 and $513 \mathrm{~K}$ corresponds to the desorption of hydrogen during the $\mathrm{REH}_{3} \rightarrow \mathrm{REH}_{2}$ phase transformation.

The second main peak ranges between 1023 and $1173 \mathrm{~K}$ and is related to the desorption of hydrogen during the $\mathrm{ReH}_{2} \rightarrow \mathrm{RE}$ phase 
Table 4

Summary of the fitting parameters of the TDS spectra.

\begin{tabular}{|c|c|c|c|c|c|c|c|c|c|c|c|c|c|c|c|}
\hline \multirow[t]{2}{*}{ Sample } & \multirow[t]{2}{*}{ TDS \# $\left(\beta\right.$ setpoint $\left(\mathrm{K} \mathrm{min}^{-1}\right)$} & \multicolumn{7}{|c|}{ Peak \#1 } & \multicolumn{6}{|l|}{ Peak \#2 } & \multirow[t]{2}{*}{$R_{f}$} \\
\hline & & $\mathrm{w}_{1}$ & $\ln \left(K_{0}\left(\min ^{-1}\right)\right)$ & $E_{A}\left(\mathrm{~kJ} \mathrm{~mol}^{-1}\right)$ & $X_{m}$ & $M$ & $N$ & $P$ & $\ln \left(K_{0}\left(\min ^{-1}\right)\right)$ & $E_{A}\left(\mathrm{~kJ} \mathrm{~mol}^{-1}\right)$ & $X_{m}$ & $M$ & $N$ & $P$ & \\
\hline \multirow[t]{4}{*}{$\mathrm{DyH}_{3}$} & $1(2.5)$ & 0.251 & 7.44 & 42.07 & 0.615 & 0.183 & 1.782 & 0.782 & 20.26 & 218.5 & 0.557 & 0.169 & 1.343 & 0.364 & 0.120 \\
\hline & $2(1)$ & 0.061 & 7.65 & 41.78 & 0.637 & 0.192 & 1.798 & 0.768 & 20.49 & 224.0 & 0.638 & 0.214 & 1.356 & 0.346 & 0.234 \\
\hline & $3(4)$ & 0.343 & 7.53 & 42.43 & 0.651 & 0.167 & 1.753 & 0.804 & 20.05 & 215.2 & 0.500 & 0.135 & 1.347 & 0.341 & 0.107 \\
\hline & $4(5.5)$ & 0.329 & 6.98 & 38.64 & 0.567 & 0.180 & 1.798 & 0.793 & 19.06 & 210.8 & 0.457 & 0.026 & 1.270 & 0.005 & 0.191 \\
\hline \multirow[t]{4}{*}{$\mathrm{HoH}_{3}$} & $1(2.5)$ & 0.339 & 16.04 & 78.49 & 0.504 & 0.101 & 1.250 & 0.138 & 24.02 & 255.0 & 0.629 & -0.004 & 1.132 & 0.284 & 0.212 \\
\hline & $2(4)$ & 0.343 & 15.70 & 77.41 & 0.543 & -0.046 & 1.220 & 0.174 & 24.02 & 255.5 & 0.556 & -0.046 & 1.149 & 0.113 & 0.256 \\
\hline & $3(1)$ & 0.331 & 15.56 & 77.10 & 0.543 & 0.000 & 1.312 & 0.167 & 23.80 & 253.2 & 0.550 & 0.000 & 0.874 & -0.116 & 0.238 \\
\hline & $4(5.5)$ & 0.344 & 16.32 & 78.70 & 0.591 & 0.000 & 0.892 & 0.119 & 24.02 & 255.0 & 0.575 & 0.000 & 0.952 & 0.016 & 0.156 \\
\hline \multirow[t]{4}{*}{$\mathrm{ErH}_{3}$} & $1(5.5)$ & 0.351 & 14.104 & 71.69 & 0.578 & -0.003 & 0.996 & 0.114 & 15.73 & 175.0 & 0.520 & -0.003 & 1.037 & 0.273 & 0.232 \\
\hline & $2(1)$ & 0.351 & 13.42 & 71.02 & 0.524 & 0.000 & 1.147 & 0.073 & 16.21 & 182.4 & 0.696 & 0.020 & 1.014 & 0.443 & 0.170 \\
\hline & $3(4)$ & 0.347 & 14.529 & 72.03 & 0.632 & 0.017 & 0.978 & 0.215 & 15.57 & 174.4 & 0.493 & 0.013 & 1.163 & 0.263 & 0.159 \\
\hline & $4(2.5)$ & 0.323 & 13.91 & 68.48 & 0.570 & -0.010 & 1.044 & 0.341 & 14.61 & 165.5 & 0.450 & 0.080 & 1.692 & 0.410 & 0.217 \\
\hline
\end{tabular}
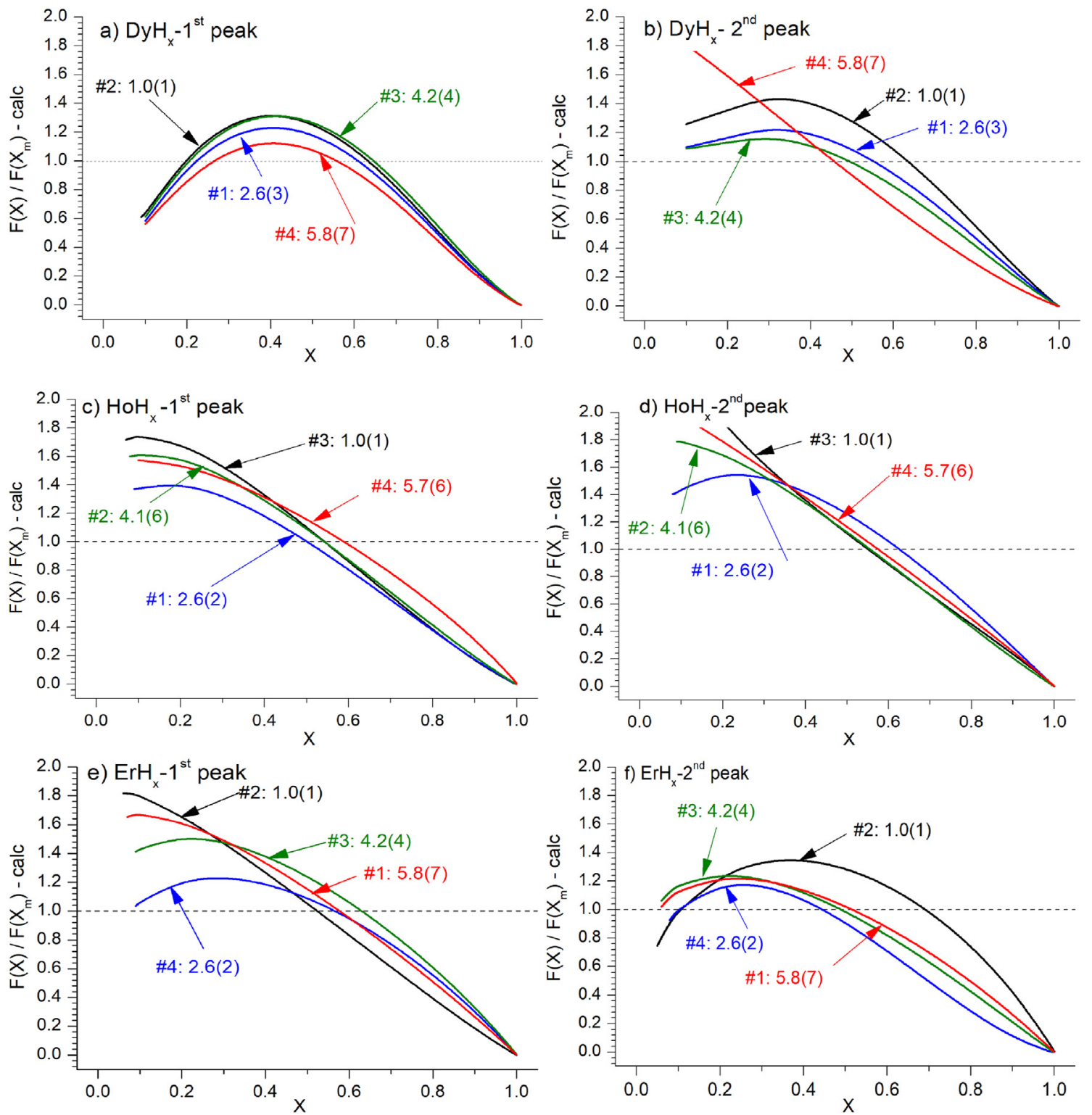

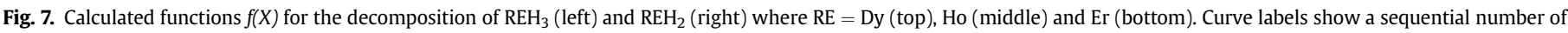

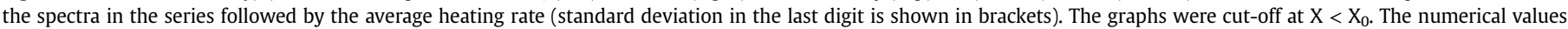
indicate the heating rate in $\mathrm{K} / \mathrm{min}$. 
Table 5

Desorption mechanisms based on the modelling of the kinetics of hydrides decomposition.

\begin{tabular}{|c|c|c|}
\hline \multirow[t]{2}{*}{$\mathrm{ReH}_{3}$} & 1st peak & 2nd peak \\
\hline & $\mathrm{REH}_{3} \rightarrow \mathrm{REH}_{2}$ & $\mathrm{REH}_{2} \rightarrow \mathrm{RE}$ \\
\hline \multirow[t]{3}{*}{$\mathrm{DyH}_{3}$} & NG2 + NG3 & NG2 + NG3 \\
\hline & Random nucleation and 3D growth & Nucleation and growth with low dimensionality \\
\hline & Nucleation is the limiting step at the beginning while diffusion controls the growth & Lower contribution of the diffusion as compared to the 1 st peak \\
\hline $\mathrm{HoH}_{3}$ & NG1 + NG3 or PB & NG1 \\
\hline \multirow[t]{2}{*}{$\mathbf{E r H}_{3}$} & NG2 & NG2 \\
\hline & Nucleation and growth with low dimensionality. & NG2 + NG3 after cycling \\
\hline
\end{tabular}

transformation.

Analysis of the experimental results presented in this study, together with the reference data for the decomposition of various rare-earth hydrides, brings a conclusion that trihydrides of "heavy" RE are characterized by lower thermal stabilities than the trihydrides of the "light" rare earth metals. Conversely, dihydrides of "heavy" RE exhibit a significantly higher thermal stability than the dihydrides of "light" RE.

In general, the desorption of hydrogen from the $\mathrm{ReH}_{3}$ and $\mathrm{ReH}_{2}$ $(\mathrm{R}=\mathrm{Dy}, \mathrm{Er})$ follows nucleation and growth mechanism.

Results of the modelling of the TDS data show that in general, the activation energies of hydrogen desorption for the $\mathrm{REH}_{3} \rightarrow \mathrm{REH}_{2}$ phase transition are lower than those of $\mathrm{ReH}_{2} \rightarrow \mathrm{RE}$ transformation. Activation energies of hydrogen desorption from $\mathrm{ReH}_{3}$ change as follows $\mathrm{DyH}_{3}<\mathrm{ErH}_{3}<\mathrm{HoH}_{3}$ while for the decomposition of $\mathrm{ReH}_{2}$ the stability of the hydrides increases in the order $\mathrm{ErH}_{2}<\mathrm{DyH}_{2}<\mathrm{HoH}_{2}$.

\section{CRediT authorship contribution statement}

S. Suwarno: Investigation, Writing - original draft, Visualization. M.V. Lototskyy: Writing - review \& editing, Formal analysis, Visualization. V.A. Yartys: Conceptualization, Supervision, Writing review \& editing.

\section{Acknowledgments}

Authors thank the Ministry of Research and Higher Education of Indonesia (RISTEK-DIKTI) for presenting the World Class Professor (WCP) 2019 award to Prof. V. A. Yartys. Financial support from EU Horizon 2020/RISE project "Hydrogen fuelled utility vehicles and their support systems utilizing metal hydrides e HYDRIDE4MOBILITY" is acknowledged. ML acknowledges support of South African Department of Science and Innovation (DSI), Hydrogen South Africa (HySA) project KP6-S01, as well as South African National Research Foundation (NRF), incentive funding grant 109092.

\section{Appendix A. Supplementary data}

Supplementary data to this article can be found online at https://doi.org/10.1016/j.jallcom.2020.155530.

\section{References}

[1] R.V. Denys, A.A. Poletaev, J.K. Solberg, B.P. Tarasov, V.A. Yartys, LaMg11 with a giant unit cell synthesized by hydrogen metallurgy: Crystal structure and hydrogenation behavior, Acta Mater. 58 (2010) 2510-2519, https://doi.org/ 10.1016/j.actamat.2009.12.037.

[2] L. Kong, X. Li, K. Young. J. Nei, X Liao, W. Li, Effects of rare-earth element additions to Laves phase-related body-centered-cubic solid solution metal hydride alloys: thermodynamic and electrochemical properties, J. Alloys Compd. 737 (2018) 174-183, https://doi.org/10.1016/j.jallcom.2017.12.058.

[3] K.-H. Young, T. Ouchi, J. Nei, D. Moghe, K.-H. Young, T. Ouchi, et al., The importance of rare-earth additions in Zr-based AB2 metal hydride alloys, Batteries 2 (2016) 25, https://doi.org/10.3390/batteries2030025.

[4] J.N. Huiberts, R. Griessen, J.H. Rector, R.J. Wijngaarden, J.P. Dekker, DG de Groot, et al., Yttrium and lanthanum hydride films with switchable optical properties, Nature 380 (1996) 231-234, https://doi.org/10.1038/380231a0.

[5] V.A. Yartys, O. Gutfleisch, V.V. Panasyuk, I.R. Harris, Desorption characteristics of rare earth $(\mathrm{R})$ hydrides $(\mathrm{R}=\mathrm{Y}, \mathrm{Ce}, \mathrm{Pr}, \mathrm{Nd}, \mathrm{Sm}, \mathrm{Gd}$ and $\mathrm{Tb})$ in relation to the HDDR behaviour of R-Fe-based-compounds, J. Alloys Compd. 253-254 (1997) 128-133, https://doi.org/10.1016/S0925-8388(96)03097-6.

[6] T.J. Udovic, Q. Huang, J.J. Rush, A neutron-powder-diffraction study of the rare-earth deuteride two-phase region, J. Alloys Compd. 356-357 (2003) 41-44, https://doi.org/10.1016/S0925-8388(03)00098-7.

[7] K. Fu, G. Li, J. Li, Y. Liu, W. Tian, X. Li, Experimental study and thermodynamic assessment of the dysprosium-hydrogen binary system, J. Alloys Compd. 696 (2017) 60-66, https://doi.org/10.1016/j.jallcom.2016.11.182.

[8] F.C. Perkins, C.E. Lundin, The holmium-hydrogen system, J. Electrochem. Soc. 115 (1968) 21-24, https://doi.org/10.1149/1.2410992.

[9] A. Mascaro, C. Toffolon-Masclet, C. Raepsaet, J.-M. Joubert, Experimental study and thermodynamic assessment of the erbium-hydrogen binary system, Calphad 41 (2013) 50-59, https://doi.org/10.1016/j.calphad.2013.01.004.

[10] J. Bloch, The hydriding kinetics of bulk metallic holmium under 1 bar $\mathrm{H} 2$ and below 570K, J. Alloys Compd. 465 (2008) 190-196, https://doi.org/10.1016/ j.jallcom.2007.10.145.

[11] I. Gabis, E. Evard, A. Voyt, I. Chernov, Zaika Yu, Kinetics of decomposition of erbium hydride, J. Alloys Compd. 356-357 (2003) 353-357, https://doi.org/ 10.1016/S0925-8388(02)01230-6.

[12] I.E. Gabis, I.A. Chernov, The Kinetics of Binary Metal Hydride Decomposition, Nova Sci Publ, 2017.

[13] M. Lototskyy, R. Denys, S. Nyallang Nyamsi, I. Bessarabskaia, V. Yartys Modelling of hydrogen thermal desorption spectra, Mater Today Proc 5 (2018) 10440-10449, https://doi.org/10.1016/j.matpr.2017.12.375.

[14] M. Lototskyy, J. Goh, M.W. Davids, V. Linkov, L. Khotseng, B. Ntsendwana, et al., Nanostructured hydrogen storage materials prepared by high-energy reactive ball milling of magnesium and ferrovanadium, Int. J. Hydrogen Energy 44 (2019) 6687-6701.

[15] S. Vyazovkin, A.K. Burnham, J.M. Criado, L.A. Pérez-Maqueda, C. Popescu, N. Sbirrazzuoli, ICTAC Kinetics Committee recommendations for performing kinetic computations on thermal analysis data, Thermochim. Acta 520 (2011) 1-19, https://doi.org/10.1016/j.tca.2011.03.034.

[16] A. Khawam, D.R. Flanagan, Solid-state kinetic models: Basics and mathematical Fundamentals, J. Phys. Chem. B 110 (2006) 17315-17328, https:// doi.org/10.1021/jp062746a.

[17] H.E. Kissinger, Reaction kinetics in differential thermal analysis, Anal. Chem. 29 (1957) 1702-1706.

[18] R.L. Blaine, H.E. Kissinger, Homer Kissinger and the Kissinger equation, Thermochim. Acta 540 (2012) 1-6.

[19] J. Šesták, G. Berggren, Study of the kinetics of the mechanism of solid-state reactions at increasing temperatures, Thermochim. Acta 3 (1971) 1-12, https://doi.org/10.1016/0040-6031(71)85051-7.

[20] J. Sharp, G. Brindley, B.N. Achar, Numerical data for some commonly used solid state reaction equations, J. Am. Ceram. Soc. 49 (1966) 379-382.

[21] S. Suwarno, J.K. Solberg, J.P. Mæhlen, R.V. Denys, B. Krogh, E. Ochoa-Fernández, et al., Non-isothermal kinetics and in situ SR XRD studies of hydrogen desorption from dihydrides of binary Ti-V alloys, Int. J. Hydrogen Energy 38 (2013) 14704-14714, https://doi.org/10.1016/j.ijhydene.2013.08.103.

[22] T. Førde, J.P. Maehlen, V.A. Yartys, M.V. Lototsky, H. Uchida, Influence of intrinsic hydrogenation/dehydrogenation kinetics on the dynamic behaviour of metal hydrides: a semi-empirical model and its verification, Int. J. Hydrogen Energy 32 (2007) 1041-1049, https://doi.org/10.1016/j.ijhydene.2006.07.015.

[23] K. Benyelloul, L. Seddik, Y. Bouhadda, M. Bououdina, N. Fenineche, H. Aourag, et al., A datamining approach to predict the formation enthalpy for rare-earth dihydrides REH2 (RE = Ce,Pr,Dy), Int. J. Hydrogen Energy 41 (2016) 11254-11263, https://doi.org/10.1016/j.ijhydene.2016.04.018.

[24] J.W. Christian, The Theory of Transformations in Metals and Alloys, Pergamon, 2002, p. 1200, https://doi.org/10.1016/B978-0-08-044019-4.X5000-4.

[25] L. Mooij, B. Dam, Nucleation and growth mechanisms of nano magnesium hydride from the hydrogen sorption kinetics, Phys. Chem. Chem. Phys. 15 (2013) 11501, https://doi.org/10.1039/c3cp51735g.

[26] P.S. Rudman, Hydrogen-diffusion-rate-limited hydriding and dehydriding kinetics, J. Appl. Phys. 50 (11) (1979) 7195-7199, https://doi.org/10.1063/ 1.325831 .

[27] J.W. Cahn, Transformation kinetics during continuous cooling, Acta Metall. 4 (1956) 572-575, https://doi.org/10.1016/0001-6160(56)90158-4. 